\title{
Optimal management of umbilical cord prolapse
}

This article was published in the following Dove Press journal: International Journal of Women's Health

\author{
Waleed Ali Sayed Ahmed \\ Mostafa Ahmed Hamdy \\ Department of Obstetrics and \\ Gynecology, Faculty of Medicine, \\ Suez Canal University, Ismailia, Egypt
}

\begin{abstract}
Umbilical cord prolapse (UCP) is an uncommon obstetric emergency that can have significant neonatal morbidity and/or mortality. It is diagnosed by seeing/palpating the prolapsed cord outside or within the vagina in addition to abnormal fetal heart rate patterns. Women at higher risk of UCP include multiparas with malpresentation. Other risk factors include polyhydramnios and multiple pregnancies. Iatrogenic UCP (up to $50 \%$ of cases) can occur in procedures such as amniotomy, fetal blood sampling, and insertion of a cervical ripening balloon. The perinatal outcome largely depends on the location where the prolapse occurred and the gestational age/birthweight of the fetus. When UCP is diagnosed, delivery should be expedited. Usually, cesarean section is the delivery mode of choice, but vaginal/instrumental delivery could be tried if deemed quicker, particularly in the second stage of labor. Diagnosisto-delivery interval should ideally be less than 30 minutes; however, if it is expected to be lengthy, measures to relieve cord compression should be attempted. Manual elevation of the presenting part and Vago's method (bladder filling) are the most commonly used maneuvers. Care should be given not to cause cord spasm with excessive manipulation. Simulation training has been shown to improve/maintain all aspects of management and documentation. Prompt diagnosis and interventions and the positive impact of neonatal management have significantly improved the neonatal outcome.
\end{abstract}

Keywords: umbilical cord prolapse, neonatal outcome, obstetric emergency, simulation training

\section{Introduction}

Umbilical cord prolapse (UCP) is an uncommon but potentially fatal obstetric emergency. Its incidence has decreased over the years and significant advances in its management have led to improved perinatal outcome. This article reviews the risk factors, perinatal outcomes, prevention and the optimal management of UCP.

\section{Definitions}

Cord presentation (fore-lying cord) is the presence of the umbilical cord (UC) between the fetal presenting part and the cervix, regardless of the membrane status (intact or ruptured). Descent of the UC through the cervix is essential for diagnosing cord prolapse. It can be either overt (past the presenting part) or occult (alongside the presenting part).

\section{Incidence}

UCP is an uncommon obstetric emergency but with potentially significant neonatal adverse outcomes. The overall incidence is reported at $0.1 \%-0.6 \%$ with higher incidences in non-cephalic presentations, multiple gestations, and earlier gestational ages. ${ }^{1}$ However, a lower incidence $(0.018 \%)$ has been reported recently ${ }^{2}$ and there is a trend toward decreasing incidence throughout the years: $0.6 \%$ in $1932,{ }^{3} 0.2 \%$ in $1990,{ }^{4}$ and

\section{Ahmed \\ Department of Obstetrics and \\ Gynecology, Faculty of Medicine, \\ Suez Canal University, Round Road, \\ Ismailia 4I I I I, Egypt \\ Email waleed.asa@gmail.com}

International Journal of Women's Health 2018:10 459-465 (c) (1) (5) 2018 Sayed Ahmed and Hamdy. This work is published and licensed by Dove Medical Press Limited. The full terms of this license are available at https://www.dovepress.com/terms.php $\mathrm{BY} \mathrm{NC}$ and incorporate the Creative Commons Attribution - Non Commercial (unported, v3.0) License (http://creativecommons.org/licenses/by-nd/3.0/). By accessing the work you
hereby accept the Terms. Non-commercial uses of the work are permitted without any further permission from Dove Medical Press Limited, provided the work is properly attributed. For permission hereby accept the Terms. Non-commercial uses of the work are permitted without any further permission from Dove Medical Press Limited, provided the work is properly attributed. For permission
for commercial use of this work, please see parazraphs 42 and 5 of our Terms (https:/wwww.dovepress com/terms php). 
$0.018 \%$ in $2016 .^{2}$ The decreasing incidence has also been documented by Gibbons et al in their retrospective review of 69 years. ${ }^{5}$ Liberal use of cesarean section (CS) for some of the most important risk factors of UCP, eg, breech presentation, may explain such decreasing trends. In addition, the decreasing occurrence of grand multiparity, better diagnosis, and improved obstetric care is linked to the falling incidence.

\section{Diagnosis}

UCP is diagnosed by seeing or palpating the prolapsed cord in addition to the presence of abnormal fetal heart $(\mathrm{FH})$ tracings. In overt UCP, the diagnosis is straightforward as the UC is seen coming out of the vagina or palpated as a soft pulsating mass during vaginal examination. However, the diagnosis of occult UCP may be more difficult. Abnormal fetal heart rate (FHR) tracings in the form of recurrent, variable, sudden severe, and/or prolonged (lasting a minute or more) decelerations may be the first sign of UCP, especially the occult type. These FHR abnormalities may occur in up to $67 \%$ of cases. ${ }^{6}$

Fore-lying umbilical cord can be diagnosed by ultrasound scan. ${ }^{2}$ Lange ${ }^{7}$ estimated an antenatal incidence of approximately 1:167 (0.6\%) live births; however, with the increased use of antepartum obstetric ultrasound, especially with color flow Doppler, the incidence could be higher. Cord presentation is transient and usually insignificant prior to 32 weeks. Large studies showed that the presence of cord presentation does not necessarily lead to cord prolapse during delivery, ${ }^{8,9}$ and that antenatal ultrasound diagnosis has a poor sensitivity and is a poor predictor of cord prolapse. ${ }^{8}$ However, when diagnosed in the third trimester, cord presentation requires follow up scans in addition to intrapartum assessment to finalize the mode of delivery.

A significant percentage of UCP cases are diagnosed at the time of amniotomy (24\%) or spontaneous rupture of membranes (SROM) (35\%). ${ }^{2}$ Attention should be paid to this complication at these times especially when abnormal FHR tracings follow membrane rupture.

Differential diagnosis of these presentations - soft mass in the vagina and sudden FHR decelerations - must be considered. The presence of fetal limb, caput succedaneum and face presentation should be excluded. In addition, numerous causes of sudden fetal bradycardia such as maternal hypotension, placental abruption, uterine rupture should be carefully evaluated.

\section{Risk factors}

Several risk factors for UCP have been identified (Table 1). Clinicians should be aware of these risk factors as this would
Table I Identified risk factors for umbilical cord prolapse

\begin{tabular}{ll}
\hline Obstetric & latrogenic \\
\hline Maternal age $\geq 35$ years & Amniotomy/SROM + high presenting part \\
Multiparity & ECV \\
Non-cephalic presentations & Placement of cervical ripening balloon \\
Preterm labor $(<37$ weeks) & Placement of intrauterine pressure \\
Low birth weight & catheter \\
Polyhydramnios & Attempted rotation of the fetal head \\
Multiple pregnancies & Inadequate prenatal care \\
Non-engaged presenting part & \\
PPROM & \\
Male sex of the newborn &
\end{tabular}

Abbreviations: ECV, external cephalic version; PPROM, preterm premature rupture of membranes; SROM, spontaneous rupture of membranes.

represent the first step in anticipating this obstetric emergency and decreasing the perinatal morbidity/mortality.

Almost half of the risk factors are iatrogenic. ${ }^{10}$ Artificial rupture of fetal membranes (ARM) especially in a multiparous case with high non-engaged head, attempted rotation of the fetal head in cases of abnormal positions, placement of intrauterine pressure catheter or fetal scalp electrode and external cephalic version are the most common examples of iatrogenic risk factors. Interventions that may cause elevation of the fetal presenting part predispose to UCP.

Other obstetric risk factors that may lead to UCP include multiparity, especially grand multiparity ( $75 \%$ of cord prolapse events in the 1940s), ${ }^{5}$ malpresentations, polyhydramnios, multiple gestations particularly in the second twin, preterm labor, and preterm premature rupture of membranes (PPROM).

The relationship between malpresentations including breech and transverse lie and UCP is well documented and is due to the poor engagement/non-engagement of the presenting part into the maternal pelvis allowing the space for the cord to prolapse. In one study, breech presentation accounted for $36.5 \%$ of UCP cases. ${ }^{3}$ Multiple gestation is another risk factor and can lead to UCP due to the abnormal fetal presentation, and it may occur with both first or second twin.

The use of cervical ripening balloon may predispose to UCP especially when filled with a large amount of fluid, and it may occur after insertion, removal or spontaneous expulsion of the balloon. ${ }^{2}$

Although prematurity is associated with increased risk of $\mathrm{UCP}$ as a result of poor application of the presenting part to the cervix, most UCP cases occur in term pregnancies. ${ }^{11}$

\section{Pathophysiology}

Compression of the UC can lead to either profound or total acute asphyxia or subacute hypoxia with different neonatal outcomes. It has been suggested that the pathophysiology of 
cord prolapse is almost an "all or none event", either causing overwhelming neurological injury and death or causing little or no cerebral injury, and this is supported by the very low incidence of stillbirth/neonatal death, neonatal encephalopathy, and cerebral palsy. ${ }^{5}$

The mechanism of fetal demise is through near-total or total acute asphyxia, which occurs when the umbilical cord is compressed between the fetal head and bony pelvis. ${ }^{12}$ This results in failure of the normal autoregulatory mechanisms of the brain resulting from hypotension and bradycardia ${ }^{5}$ and leads to the failure of cerebral blood redistribution, with cell death of the brainstem - the most metabolically active area of the brain. This is unlike cases of subacute hypoxia where blood can be distributed to the more vital areas of the brain, sparing the brainstem and resulting in minimal or short-lasting neurological manifestation.

\section{Management}

Umbilical cord prolapse is an acute obstetric emergency that mandates delivery of the baby as quickly as possible. The route of delivery is usually by CS but vaginal/instrumental delivery can be attempted if deemed quicker. The Royal College of Obstetricians and Gynecologists (RCOG) recommends the diagnosis-to-delivery interval (DDI) to be less than 30 minutes in order to optimize the perinatal outcome, particularly in the presence of evidence of fetal compromise. ${ }^{1}$ However, further decreases of DDI below the 30-minute limit do not necessarily improve the neonatal outcome. ${ }^{6}$ Prompt recognition and rapid action are the mainstays of managing this emergency.

When UCP is diagnosed, it is important to amass personnel for help. As emergency CS is typically the treatment of choice, so the anesthetist and operation room staff need to be informed promptly to get ready. Continuous FHR monitoring and recording are carried out until delivery. $\mathrm{O}_{2}$ supplementation by face mask improves the $\mathrm{O}_{2}$ delivery to the baby.

If the woman is in the first stage of labor or early in the second stage, prompt cesarean delivery is recommended. If vaginal delivery is imminent or instrumental delivery is possible, they can be contemplated.

There are several measures to relieve cord compression which should be carried out till CS is performed (Box 1). These measures include manual elevation of the fetal presenting part using two fingers or the whole hand through the vagina, the positioning of the patient in steep Trendelenburg, exaggerated Sim's position ${ }^{13}$ or knee-chest position, filling the bladder with 500-700 cc or more of saline and the now out-of-favor method of cord replacement. Care should be exercised not to excessively manipulate the cord as this
Box I Principles of management of umbilical cord prolapse

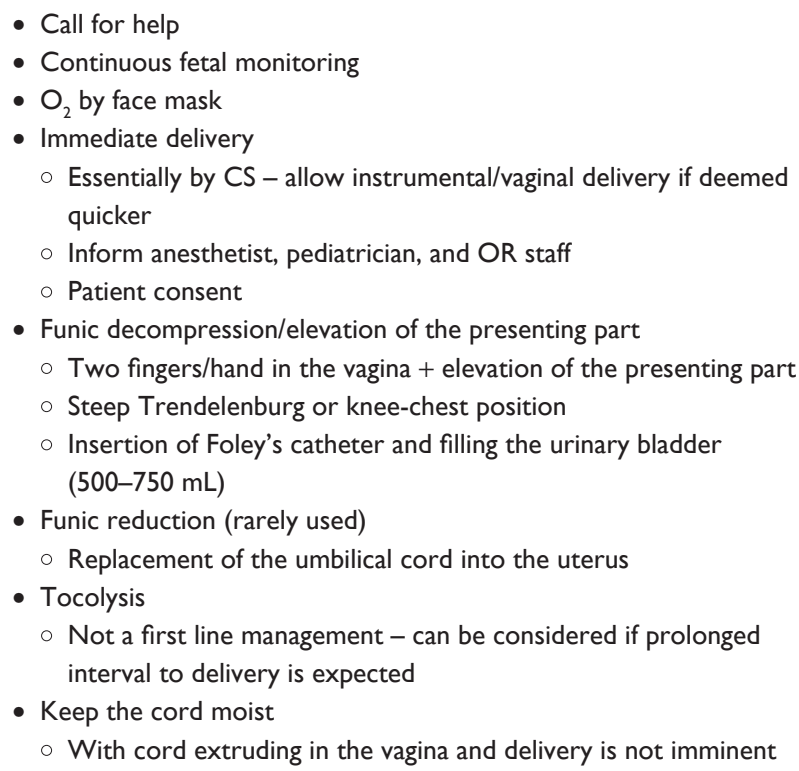

can result in umbilical artery vasospasm and do more harm than good.

Vago $^{14}$ described successfully using bladder filling as a means of relieving cord compression. This method is especially useful if the cord is prolapsed in a remote area where delivery is not imminent. Filling the bladder with $500 \mathrm{cc}$ or more of normal saline or when the bladder is visibly seen above the pubic area would relieve cord compression by elevating the presenting part and may help in decreasing uterine contractions. ${ }^{14}$ The addition of tocolytics in the form of intravenous ritodrine infusion (250-400 $\mu \mathrm{g} / \mathrm{min})$ was shown to improve the FHR tracing and the Apgar score $\geq 7$ at 5 minutes. ${ }^{15}$

Manual cord replacement (funic reduction) to above the presenting part is rarely carried out nowadays. This maneuver could be tried while preparations for an emergency CS are being made up. If cord prolapse occurred in a remote area, replacement could be tried till CS is done. However, Vago's method would be the measure of choice to reduce the cord compression. Barrett ${ }^{16}$ in his small series of cord replacements in the management of UCP recommended certain criteria before this procedure is contemplated: a short segment of the cord $(<25 \mathrm{~cm})$, cervical dilatation $\geq 4 \mathrm{~cm}$, the presenting part could be easily elevated above -1 station and rapid completion of the procedure (within 2 minutes).

Tocolytics had been used with the aim of decreasing the uterine contractions, relieving the pressure on the prolapsed cord in addition to improving the placental perfusion and hence the blood supply to the baby, which might be helpful if DDI is expected to be prolonged. ${ }^{17}$ However, tocolytics may 
Box 2 Contraindications for immediate delivery

- Fetal demise

- Lethal fetal anomalies

- Pre-viable gestation

cause uterine atony following delivery and in cases where UCP occurs in the hospital, expedient delivery should be undertaken without recourse to tocolytics.

There are several case reports of conservative management of cord prolapse and all are in pre-viable gestation fetuses with the aim of prolongation of pregnancy. ${ }^{18,19}$ In these cases, the extreme prematurity and low birthweight may have resulted in less cord compression, minimizing asphyxia and improving fetal outcome. ${ }^{18}$ Pre-viable gestation is one of the contraindications for immediate delivery in cases of UCP (Box 2); the others being fetal demise and lethal fetal anomalies. Conservative treatment of UCP should be reserved in carefully selected cases after full counselling of the parents about the prognosis.

A special note on unstable lie is worth mentioning as it is particularly relevant to UCP. When unstable lie is diagnosed after 37 weeks of gestation, the risks, especially UCP, should be clearly explained to the pregnant woman and the management options offered. These include admission at 38-39 weeks gestation, elective CS, expectant management or active management in the form stabilizing induction, ie, external version then induction of labor. If vaginal delivery is contemplated, care should be exercised during ARM and vaginal examination should be carried out if SROM occurred to exclude cord prolapse and ascertain the presentation.

The urgent nature of the management of UCP that often ends by emergency CS can be traumatic to the woman and those accompanying her. Debriefing the patient and her partner regarding the course of events is important, explaining why this happened and if it has any implications related to future deliveries, eg, repeat CS or recurrence of UCP. If antenatal diagnosis of cord presentation was made, detailed discussion and advice about the management of the remaining antenatal period, mode of delivery and intrapartum care - if vaginal delivery is being contemplated - are of paramount importance.

\section{Perinatal outcome}

\section{Perinatal mortality and morbidity}

The perinatal mortality and morbidity largely depend on the location where the prolapse occurred (inside or outside the hospital facility) and the gestational age/birthweight of the fetus. Where the prolapse occurs outside the hospital; mortality rates as high as $44 \%$ have been reported, compared to $3 \%$ if this occurs inside the hospital. ${ }^{3}$ The perinatal mortality rate was estimated at $6.8 \%$ and was likely to occur in nulliparous women. ${ }^{20}$ Premature infants and those of low birth weight have less favorable outcomes and have twice the risk of perinatal mortality compared to those without UCP. ${ }^{4}$

UCP can be associated with perinatal morbidity, including low 5-minute Apgar scores, assisted ventilation requirement, low cord $\mathrm{pH}$, meconium aspiration, hyaline membrane disease, neonatal seizures, neonatal encephalopathy (2\%), and cerebral palsy $(0.43 \%) .{ }^{5}$ However, a recent study estimated a neonatal encephalopathy incidence of only $0.32 \%{ }^{20}$ Neonatal encephalopathy was defined as either neonatal seizures or two of the following lasting longer than $24 \mathrm{~h}$ : abnormal consciousness, difficulty maintaining respiration or feeding (both of central origin), or abnormal tone/ reflexes. ${ }^{20}$ An increased incidence of placental abruption and meconium-stained amniotic fluid has been reported which can result in increased neonatal morbidity. ${ }^{11}$

There is a trend toward decreasing perinatal mortality and morbidity and overall survival over the years. In one study, stillbirth decreased from $48 \%$ (1940s) to $2.1 \%$ (2000s) and overall survival improved to 94\% (2000s) from $46 \%$ (1940s). ${ }^{5}$ Improved diagnosis and interventions and the positive impact neonatal management explain these improvements.

\section{Predictors of the outcome}

Several predictors of perinatal outcome have been identified including the DDI, the FHR changes, and the mode of delivery (Table 2).

DDI less than 30 minutes is associated with lower mortality rates in infants $>2,500 \mathrm{~g}^{21}$ and higher Apgar scores. ${ }^{6,22}$ However, hypoxemic encephalopathy had been reported with very short DDI ( $<15$ minutes), which suggests that other factors may play part in the outcome. ${ }^{23}$ Such factors include the occurrence of prolapse preceding diagnosis by a significant length of time, the degree of cord compression, and the presence of fetal compromise.

Table 2 Predictors of perinatal outcome

\begin{tabular}{lll}
\hline Predictors & $\begin{array}{l}\text { Favorable } \\
\text { outcome }\end{array}$ & $\begin{array}{l}\text { Less favorable } \\
\text { outcome }\end{array}$ \\
\hline Location of the cord prolapse & $\begin{array}{l}\text { Inside the hospital } \\
\text { Diagnosis-to-delivery interval }\end{array}$ & $\begin{array}{l}\text { Outside the hospital } \\
\text { Birth weight }\end{array}$ \\
Mode of delivery* & $>2,500 \mathrm{~g}$ & $>30$ minutes \\
& Cesarean delivery & Vaginal/operative \\
& & delivery \\
\hline
\end{tabular}

Note: *Before full cervical dilatation. 
The location where UCP occurs can have an effect on the perinatal outcome. Occurrence in the hospital with rapid recourse to delivery is associated with improved perinatal outcome, compared to occurring at a remote location. Those fetuses who maintain normal heart rate tracings at the time of UCP have lower incidence of adverse neonatal outcome. ${ }^{24}$

Cesarean delivery is significantly associated with decreased perinatal mortality and morbidity compared to vaginal delivery. Critchlow et $\mathrm{al}^{25}$ found that delivery by emergency CS significantly reduced the risks of an Apgar score $<3$ at five minutes and neonatal mortality when compared to spontaneous normal delivery. However, spontaneous or operative vaginal deliveries may be contemplated in the second stage of labor if deemed feasible, quick, and highly likely to succeed. When operative vaginal delivery is contemplated, the same rules for applying forceps or ventose should be maintained, eg, full cervical dilatation, and engaged head.

\section{Long-term disability}

UCP has been shown to have an all-or-nothing effect on the neonatal outcome and the evidence for long term disability remains inconclusive. There is a very low incidence of neonatal encephalopathy; ${ }^{20}$ however, long-term sequelae in the surviving infants in the form of cerebral palsy of the spastic quadriplegic and dyskinetic types have been reported in both preterm and term infants. ${ }^{26}$

\section{Prevention}

Knowledge of the risk factors of UCP does not significantly decrease its occurrence; ${ }^{6}$ however, the anticipation of this problem can lead to improvement of fetal morbidity and mortality. Of note, cord prolapse can occur in pregnancies without obvious risk factors, ${ }^{1,4}$ which renders this complication unpreventable (Box 3).

Caution should be exercised during interventions that carry a high risk of UCP. Amniotomy in a patient where the head is not well applied is better postponed, unless it is necessary, where it should be carried out with caution. A controlled rupture by a more experienced obstetrician allows the

Box 3 Strategies for prevention of cord prolapse

- Awareness and anticipation of the risk factors

- Antenatal ultrasound diagnosis in high risk patients

- Vigilance during procedures that increase the risk of UCP, eg,

- Amniotomy

- Manual rotation of the head

- Application of cervical ripening balloon and fetal scalp electrodes

Abbreviation: UCP, umbilical cord prolapse. drainage of liquor in a slow gush. Some would advise the use of hypodermic needle or pudendal block trumpet to get a slow and controlled drain of amniotic fluid. ${ }^{27}$

Manipulation of the fetal head, especially if non-engaged, should also be kept to minimum and dealt with extra care. Interventions such as placement of fetal scalp electrode or intrauterine pressure catheter as well as the application of cervical ripening balloon may result in elevation of the fetal head and lead the cord to prolapse. It is difficult to abolish the risk of UCP with these interventions but the anticipation of this complication may lead to better diagnosis, earlier intervention, and better perinatal outcome.

Antenatal ultrasound diagnosis of cord presentation should be sought, especially in pregnancies at higher risk of cord prolapse such as those with abnormal presentations, preterm labor, and PPROM. This has the value of counselling women regarding the complications of cord prolapse and what to do if the membrane ruptures. However, intervention, ie, CS based on ultrasound diagnosis, has not been yet justified.

Continuous FHR monitoring in high-risk women would not prevent UCP as such but it will help in early diagnosis when FHR abnormalities are detected.

Perinatal mortality was shown to be higher with planned out-of-hospital birth compared to planned in-hospital birth; however, both settings carried a low risk of perinatal death. ${ }^{28}$ In a study from the Netherlands, eight cases of UCP in primary midwifery care were diagnosed in one year resulting in one infant death from severe birth asphyxia, giving a perinatal mortality incidence of $12.5 \%{ }^{29}$ Despite the low number of cases and the well-established birth in primary care in the Dutch obstetrical system, this incidence is considered high. Women should be informed about the risks of delivery in non-hospital settings and careful selection of low risk women may further decrease obstetric complications, including UCP.

\section{Simulation training for umbilical cord prolapse}

Despite a documented decrease in the incidence of UCP, this potentially fatal obstetric emergency will continue to occur. Simulation training in obstetric emergencies helps to improve teamwork, awareness, knowledge, and skills in life-threatening and/or uncommon obstetric complications. ${ }^{30}$

The aim of simulation training in such an obstetric emergency is to improve the team work in order to optimize the neonatal outcome. In addition, training involves maneuvers to alleviate cord compression, effective communication 


\section{Box 4 Objectives of simulation training}

- Recognize those women at highest risk of UCP

- Quick assembling of health care personnel involved in the management

- Practice the maneuvers to alleviate cord compression

- Improve the diagnosis-to-delivery interval to less than 30 minutes

- Ensure effective and comprehensive patient and family understanding

- Improve documentation

Abbreviation: UCP, umbilical cord prolapse.

between those involved in the management, the use of spinal anesthesia and event documentation regarding the presence or absence of fetal distress (Box 4).

Studies examining the effect of simulation training on the outcome of UCP revealed different results. Siassakos et al found that annual training was associated with improved management of cord prolapse in the form of improvement of DDI (from 25 to 14.5 minutes) as well as in Apgar scores below 7 at 5 minutes. ${ }^{31}$ However, Copson et al found nonsignificant improvements in all aspects of management apart from an increase in the number of babies with Apgar scores $<7$ at 5 minutes, and explained this by the high standard care prior to training. ${ }^{32}$ In their case, Copson et al concluded that simulation training would maintain the high standard of care in their units.

Documentation is very important for medico-legal issues. An identified member of the managing team should be responsible for recording the sequence of events, interventions, and maternal and neonatal outcomes. Documentation items are shown in Box 5.

\section{Conclusion}

Umbilical cord prolapse is an acute obstetric emergency that is associated with increased perinatal morbidity and mortality, thus requiring rapid identification and intervention. Once diagnosed, the most rapid method of delivery should be

\section{Box 5 Documentation items}

- Time of occurrence of cord prolapse

- Fetal status at cord prolapse and till delivery

- Condition of the cord (color, pulsations)

- Time of notification/arrival of obstetrician and other health care personnel

- Maneuvers carried out to relieve cord compression

- Fetal response to interventions/maneuvers

- Time of entering the theatre and start of CS - if carried out

- Type of anesthesia

- Diagnosis-to-delivery interval

- The condition of the baby at delivery including cord $\mathrm{pH}$

- Neonatal outcome

Abbreviation: CS, cesarean section. carried out. If delivery is not imminent, alleviation of cord compression should be contemplated by elevating the presenting part either manually or by bladder filling in addition to repositioning of the patient. Prior knowledge of risk factors as well as regular simulation training that helps develop team work, DDI and documentation will benefit those unfamiliar with the condition to improve their management and hence the neonatal outcome.

\section{Disclosure}

The authors report no conflicts of interest in this work.

\section{References}

1. Royal College of Obstetricians and Gynecologists. Umbilical Cord Prolapse: Green-top Guideline No. 50. London, UK: RCOG, 2014.

2. Hasegawa J, Ikeda T, Sekizawa A, et al; Japan Association of Obstetricians and Gynecologists, Tokyo, Japan. Obstetric risk factors for umbilical cord prolapse: a nationwide population-based study in Japan. Arch Gynecol Obstet. 2016;294:467-472.

3. Koonings PP, Paul RH, Campbell K. Umbilical cord prolapse: a contemporary look. J Reprod Med. 1990;35:690-692.

4. Lin MG. Umbilical cord prolapse. Obstet Gynecol Surv. 2006;61: 269-277.

5. Gibbons C, O’Herlihy C, Murphy JF. Umbilical cord prolapse changing patterns and improved outcomes: a retrospective cohort study. BJOG. 2014;121:1705-1709.

6. Murphy DJ, MacKenzie IZ. The mortality and morbidity associated with umbilical cord prolapse. Br J Obstet Gynaecol. 1995;102:826-830.

7. Lange IR. Determine cord position in malpresentation. Contemp Obstet Gynecol. 1987;29:112.

8. Ezra Y, Strasberg SR, Farine D. Does cord presentation on ultrasound predict cord prolapse? Gynecol Obstet Invest. 2003;56:6-9.

9. Lange IR, Manning FA, Morrison I, Chamberlain PF, Harman CR. Cord prolapse: is antenatal diagnosis possible? Am J Obstet Gynecol. 1985; 151:1083-1085.

10. Usta IM, Mercer BM, Sibai BM. Current obstetrical practice and umbilical cord prolapse. Am J Perinatol. 1999;16:479-484.

11. Behbehani S, Patenaude V, Abenhaim HA. Maternal risk factors and outcomes of umbilical cord prolapse: a population-based study. J Obstet Gynaecol Can. 2016;38:23-28.

12. Redline RW. Disorders of placental circulation and the fetal brain. Clin Perinatol. 2009;36:549-559.

13. Bord I, Gemer O, Anteby EY, Shenhav S. The value of bladder filling in addition to manual elevation of presenting fetal part in cases of cord prolapse. Arch Gynecol Obstet. 2011;283:989-991.

14. Vago T. Prolapse of the umbilical cord: a method of management. Am J Obstet Gynecol. 1970;107:967-969.

15. Katz Z, Shoham Z, Lancet M, Blickstein I, Mogilner BM, Zalel Y. Management of labor with umbilical cord prolapse: a 5-year study. Obstet Gynecol. 1988;72:278-281.

16. Barrett JM. Funic reduction for the management of umbilical cord prolapse. AM J Obstet Gynecol. 1991;165:654-657.

17. Katz Z, Lancet M, Borenstien R. Management of labor with umbilical cord prolapse. Am J Obstet Gynecol. 1982;142:239-241.

18. Leong A, Rao J, Opie G, Dobson P. Fetal survival after conservative management of cord prolapse for three weeks. BJOG. 2004;111: 1476-1477.

19. Poetker DM, Rijhsinghani A. Fetal survival after umbilical cord prolapse for more than three days a case report. J Reprod Med. 2001;46: 776-778.

20. Hehir MP, Hartigan L, Mahony R. Perinatal death associated with umbilical cord prolapse. J Perinat Med. 2017;45(5):565-570. 
21. Bock JE, Wiese J. Prolapse of the umbilical cord. Acta Obstet Gynecol Scand. 1972;51:303-308.

22. Alouini S, Mesnard L, Megier P, Lemaire B, Coly S, Desroches A. [Management of umbilical cord prolapse and neonatal outcomes]. $J$ Gynecol Obstet Biol Reprod (Paris). 2010;39(6):471-477. French.

23. Prabulos AM, Philipson EH. Umbilical cord prolapse. Is the time from diagnosis to delivery critical? J Reprod Med. 1998;43:129-132.

24. Nizard J, Cromi A, Molenddijik H, Arabin B. Neonatal outcome following prolonged umbilical cord prolapse in preterm premature rupture of membranes. BJOG. 2005;112:833-836.

25. Critchlow CW, Leet TL, Benedetti TJ, Daling JR. Risk factors and infant outcomes associated with umbilical cord prolapse: a population-based case-control study among births in Washington State. Am J Obstet Gynecol. 1994;170:613-618.

26. Gilbert WM, Jacoby BN, Xing G, Danielsen B, Smith LH. Adverse obstetric events are associated with significant risk of cerebral palsy. Am J Obstet Gynecol. 2010;203:328.e1-5.
27. Holbrook BD, Phelan ST. Umbilical cord prolapse. Obstet Gynecol Clin North Am. 2013;40:1-14.

28. Snowden JM, Caughey AB, Cheng YW. Planned out-of-hospital birth and birth outcomes. N Engl J Med. 2016;374(22):2190-2191.

29. Smit M, Zwanenburg F, van der Wolk S, Middeldorp J, Havenith B, van Roosmalen J. Umbilical cord prolapse in primary midwifery care in the Netherlands; a case series. Pract Midwife. 2014;17(6):24-27.

30. Fransen AF, van de Ven J, Merién AE, et al. Effect of obstetric team training on team performance and medical technical skills: a randomised controlled trial. BJOG. 2012;119(11):1387-1393.

31. Siassakos D, Hasafa Z, Sibanda T, et al. Retrospective cohort study of diagnosis-delivery interval with umbilical cord prolapse: the effect of team training. BJOG. 2009;116:1089-1096.

32. Copson S, Calvert K, Raman P, Nathan E, Epee M. The effect of a multidisciplinary obstetric emergency team training program, the In-Time course, on diagnosis to delivery interval following umbilical cord prolapse - A retrospective cohort study. Aust N Z J Obstet Gynaecol. 2017;57:327-333.
International Journal of Women's Health

\section{Publish your work in this journal}

The International Journal of Women's Health is an international, peerreviewed open-access journal publishing original research, reports, editorials, reviews and commentaries on all aspects of women's healthcare including gynecology, obstetrics, and breast cancer. The manuscript management system is completely online and includes

\section{Dovepress}

a very quick and fair peer-review system, which is all easy to use. Visit http://www.dovepress.com/testimonials.php to read real quotes from published authors.

\footnotetext{
Submit your manuscript here: http://www.dovepress.com/international-journal-of-womens-health-journal
} 